\title{
Pain assessment in a geriatric psychiatry program
}

\author{
Paul Stolee $\mathrm{PhD}^{1,2}$, Loretta M Hillier $\mathrm{MA}^{2,3}$, Jacquelin Esbaugh $\mathrm{MA}^{2,3}$, Nancy Bol MScN${ }^{4}$, Laurie McKellar RN (EC) ${ }^{3}$, \\ Nicole Gauthier $\mathrm{MA}^{5}$, Maggie C Gibson $\mathrm{PhD}^{2,6}$
}

\begin{abstract}
P Stolee, LM Hillier, J Esbaugh, et al. Pain assessment in a geriatric psychiatry program. Pain Res Manage 2007;12(4):273-280.
\end{abstract}

BACKGROUND: The assessment of pain in older persons with psychiatric illness is particularly challenging for health care professionals. There are few well-tested pain assessment tools for this population.

OBJECTIVES: A study was conducted to explore pain assessment and management issues in geriatric psychiatry.

METHODS: Seventy-four staff members of a geriatric psychiatry service at Regional Mental Health Care London, St Joseph's Health Care London, London, Ontario completed a survey to assess current pain assessment and management practice for geriatric psychiatry patients, and to identify indicators used to assess pain in this population. The results of the survey were later shared with members of the program's pain management team in a focus group discussion to explore opportunities on how to transfer these findings into clinical practice.

RESULTS: The majority of survey respondents (91.8\%) agreed that pain assessment and management could be improved for patients; only $14.9 \%$ reported that there was a consistent approach to pain management. Misconceptions and attitudes about pain, lack of easily administered pain tools, inconsistent monitoring of pain, and lack of documentation of pain symptoms and indicators were identified as significant barriers to optimal pain management for their patients. A number of behaviours indicative of pain were identified but emphasis was placed on recognition of changes from usual behaviour.

CONCLUSIONS: The findings of the present study highlight the need for a comprehensive, practical and consistent approach to pain assessment and management, and provide insight into the critical components, including behavioural indicators, that could be incorporated into a pain protocol to be used with this population.

Key Words: Geriatrics; Management; Measurement; Pain assessment; Pain behaviours; Psychiatry

\section{Évaluation de la douleur dans un programme de gérontopsychiatrie}

HISTORIQUE : L'évaluation de la douleur chez les personnes âgées qu présentent une maladie psychiatrique pose un défi particulier aux professionnels de la santé car il existe peu d'outils d'évaluation de la douleur bien validés pour cette population.

OBJECTIF : Une étude a été réalisée dans le but d'explorer l'évaluation et la prise en charge de la douleur en gérontopsychiatrie.

MÉTHODES : Soixante-quatorze membres du personnel d'un service de gérontopsychiatrie du Regional Mental Health Care London - St. Joseph's Health Care London, de London, en Ontario, ont répondu à un questionnaire portant sur leur façon actuelle d'évaluer et de prendre en charge la douleur chez leurs patients âgés atteints de troubles psychiatriques et sur les indicateurs qu'ils utilisent pour évaluer la douleur chez cette population. Les résultats de l'enquête ont par la suite été partagés avec les membres de l'équipe de prise en charge de la douleur au sein du programme sous forme de discussion de groupe afin de voir comment les connaissances acquises par le biais de l'enquête pouvaient être appliquées dans la pratique clinique. RÉSULTATS : La majorité des répondants (91,8\%) ont convenu que l'évaluation et la prise en charge de la douleur pouvaient être améliorées chez ces patients; $14,9 \%$ seulement ont mentionné utiliser une approche structurée pour la prise en charge de la douleur. Parmi les obstacles les plus importants à la prise en charge optimum de la douleur chez leurs patients, ils ont mentionné entre autres : les idées préconçues et les préjugés à propos de la douleur, l'absence d'outils d'évaluation faciles à utiliser, le manque de cohésion dans la surveillance de la douleur et le manque de documentation quant aux symptômes et indicateurs de la douleur. Un certain nombre de comportements associés à la douleur ont été identifiés, mais on a plutôt mis l'accent sur la reconnaissance des changements comportementaux.

CONCLUSIONS : Les observations tirées de la présente étude mettent en lumière la nécessité d'élaborer une approche globale, pratique et cohérente à l'évaluation et à la prise en charge de la douleur et elles nous renseignent sur certains éléments cruciaux, notamment les indicateurs comportementaux, qui devraient être incorporés dans tout protocole d'évaluation de la douleur auprès de cette population.

sensory impairment (7). Older persons may express pain in ways that are misinterpreted or unrecognized by health care providers and informal caregivers (3). Those with substantial cognitive dysfunction have lost any meaningful context for pain, and accordingly may have extreme behavioural responses to pain (8). Many pain cues, such as depression, anxiety and isolation, are also psychiatric presentations, making accurate pain assessment a challenge. Aggression, agitation, resistance and irritability, which may be expressions of pain, are behaviours cated by multiple comorbidities, medications, depression and

${ }^{1}$ School of Optometry and Department of Health Studies and Gerontology, University of Waterloo, Waterloo; ${ }^{2}$ Aging, Rehabilitation Eु Geriatric Care Research Centre of the Lawson Health Research Institute, London; ${ }^{3}$ Specialized Geriatric Services of Southwestern Ontario, St Joseph's Healthcare London; ${ }^{4}$ Geriatric Psychiatry Program, Regional Mental Health Care London; ${ }^{5}$ Quality Management and Clinical Decision Support, St Joseph's Healthcare London; 'Veteran's Care Program, Parkwood Hospital, St Joseph's Healthcare London, London, Ontario

Correspondence: Dr Paul Stolee, School of Optometry, University of Waterloo, 200 University Avenue West, Waterloo, Ontario

N2L 3G1. Telephone 519-888-4567 ext 37559, fax 519-746-2510, e-mail stolee@uwaterloo.ca 
often attributed to cognitive impairment. Psychotropic medications that are often prescribed to manage these behaviours may mask pain-related symptoms and further impede pain assessment and management (9).

It has been recommended that comprehensive pain assessment in older persons should, when possible, include both self-report and observational methods (10). While some selfreport tools are available to provide meaningful reflections of pain intensity for persons with mild to moderate cognitive impairment, these types of tools are not particularly useful for those with severe psychiatric illnesses or cognitive impairments $(11,12)$. For persons unable to self-report, behavioural observations of pain can provide insight into the presence of pain.

Although several reviews have revealed that there is limited evidence for the reliability and validity of behavioural tools available for use with older persons with cognitive impairment $(12,13)$, continued research in this area holds promise for the development of clinically useful observational tools for use with this population to assess acute and chronic pain conditions. Recent research examining the psychometric properties of observational pain scales, such as the Pain Assessment in Advanced Dementia scale (PAINAD), Pain Assessment Checklist for Seniors with Limited Ability to Communicate (PACSLAC) and the DOLOPLUS-2, for use with older nursing home residents with dementia undergoing influenza vaccination, have found these tools to be clinically useful and psychometrically sound (14). Similarly, preliminary research on the PACSLAC scale conducted with long-term care residents suggests its usefulness to discriminate painful events and nonpainful events (15).

A wide variety of facial expressions, verbalizations, vocalizations, body movements, changes in interpersonal interactions and activity patterns or routines and changes in mental function have been identified as common pain behaviours in older persons with cognitive impairment (16). Several studies conducted with persons who have moderate to severe cognitive impairments during invasive procedures (17) and movement and sedentary activities (18) have found that facial behaviours can effectively communicate the presence of pain. Moreover, pain behaviours - such as guarded movements may reflect anticipation of pain as individuals protect themselves during physically demanding activities (18). Although observational methods exist to assess pain through body movements and facial expressions (eg, the Facial Action Coding Scheme), these tools are labour intensive and require special training, which limits clinical value (15). Our review of pain tools revealed that vocalizations, facial expression and body language are commonly assessed by available behavioural measures, while fewer measures include changes to behaviour and mood, physiological and physical changes, and reactions during specific activities of daily living (13). While these behaviours have been identified as useful in detecting pain in older adults with cognitive impairment, little is known about their usefulness in assessing pain in older persons with other types of psychiatric illness.

Health care providers caring for older persons with psychiatric illness within a geriatric psychiatry service at the Regional Mental Health Care facility (St Joseph's Health Care London) were interested in developing a pain assessment approach for use with their clinical population, but were challenged by many of the pain assessment issues mentioned above.
The purposes of the present study are to explore current pain assessment and management practices for patients in a geriatric psychiatry program, to identify the most important indicators used by clinicians to assess pain in patients in this clinical population, and to use these results to inform the development of a clinical pain protocol.

\section{METHODS}

Health care providers within the Geriatric Psychiatry Program London (GPP) at Regional Mental Health Care London, St Joseph's Health Care London, London, Ontario, were surveyed to explore pain assessment and management issues and to identify indicators of pain in their clinical population. The GPP consists of four units with a total of 98 beds evenly distributed across the units. Two of the units primarily admit patients with dementia; one of these units cares primarily for patients with aggressive behaviours. Patients in the other two units have more varied psychiatric diagnoses, with one of these units caring primarily for depressed patients. The average age of the patients is 75 years and the average length of stay is 105 days. Surveys were distributed to all full-time and part-time staff working in the four units within the GPP, including registered nurses (RNs), registered practical nurses (RPNs), physicians and allied health professionals such as social workers, occupational therapists, occupational therapy assistants, physiotherapists, physiotherapy assistants, therapeutic recreation therapists, pharmacists and chaplains $(n=136)$.

The self-administered surveys were paper-based and anonymous. The survey consisted of four sections. In part 1, respondents used five-point Likert scales ( $1=$ strongly disagree to $5=$ strongly agree) to indicate the extent to which they agreed or disagreed with a series of statements that gathered information about their perceptions of how common pain is for patients in their program (eg, "Pain is a problem for many of the patients in my program"), attitudes about pain assessment and management (eg, "I think effective pain management involves all disciplines"; "I find it difficult to assess pain in the patients in my program"), and how pain was currently addressed in their program (eg, "In my program, all patients are assessed for pain at admission"; "My unit has a standardized, or consistent, approach to managing pain in patients").

Using a similar rating scale in part 2 of the survey, respondents were asked to indicate the extent to which they agreed or disagreed with a list of items posing a potential barrier to adequate pain assessment and management (eg, "Lack of appropriate assessment tools"; "Inconsistent monitoring of pain"). In part 3 of the survey, again using the same rating scale, respondents were provided with a list of 37 potential pain indicators and were asked to rate the extent to which they agreed or disagreed that they could be indicators of pain for patients in their program. Respondents were given the opportunity to provide any additional pain indicators that were not already identified. Demographic information was also collected (employment status, discipline, the unit on which they primarily worked and experience in geriatrics or in geriatric psychiatry).

To support the content validity of the survey, the questions used were based on issues or similar survey questions reported in the literature (19-24). Also, the pain indicators are those identified in the literature as common for older adults $(16,25)$. Authors (PS, LMH, NG, JE) developed an initial draft of the survey; several clinicians who have extensive clinical experience 
working in geriatrics and who are considered pain experts in their field reviewed the survey for content and face validity, clarity of items and accuracy. Internal consistency (Cronbach's alpha) of the pain assessment and management issues, potential barriers and pain indicators were $0.75,0.88$ and 0.96 , respectively. Coefficients of 0.70 or greater are generally accepted as evidence of adequate internal consistency (26).

Using SPSS (version 10.0; SPSS Inc, USA), means, SDs and frequencies were calculated for all survey questions. As appropriate, ANOVA and $\chi^{2}$ analyses were used to identify differences based on demographic information (unit, discipline, experience). Post hoc tests of group means were conducted using the widely used Tukey's honestly significant difference test (27).

Once the data were collected and analyzed, members of a newly created interdisciplinary Pain Management Team $(n=30)$ within the GPP were invited to participate in a focus group interview led by two authors (LHM, NB) to discuss the study results and explore opportunities for translating the findings into clinical practice. Eleven individuals participated in the interview (RNs, $n=7$; RPNs, $n=1$; occupational therapist, $\mathrm{n}=1$; therapeutic recreationist, $\mathrm{n}=1$; social worker, $\mathrm{n}=1$ ). Absent from the focus group interview were representatives from physician and physiotherapist members of the committee.

Transcribed audiotapes of the focus group interviews were analyzed using a qualitative naturalistic inquiry approach (28); reoccurring themes were identified using an inductive analysis approach to qualitative data analysis (29). The results of the interview were shared with participants as a member check (28) to examine and provide feedback on the findings and interpretations; validity was supported by the lack of negative feedback regarding the interpretation of the data.

The present study was approved by the Research Ethics Board for Health Sciences Research Involving Human Subjects, University of Western Ontario, and by the hospital research review committee.

\section{RESULTS}

Respondent characteristics

Seventy-four GPP staff completed the survey (54\% response rate). Almost all survey respondents were employed full-time $(\mathrm{n}=71 ; 97.3 \%)$. The majority were RNs $(\mathrm{n}=26 ; 36.1 \%)$ and RPNs $(n=29 ; 40.3 \%)$; the remaining respondents were physicians $(n=3 ; 4.2 \%)$ and allied health professionals $(n=14$; $19.4 \%$ ). The distribution of RNs, RPNs and physicians participating in the present study were roughly representative of these disciplines in the GPP as a whole. Almost all allied health professionals working in the GPP (14 of 16; 87.5\%) completed the survey. Respondents were distributed fairly evenly across the units: $24(32.4 \%)$ worked in the two units caring for patients with dementia, 21 (28.4\%) worked in the two units caring for patients with varied psychiatric diagnoses, and $16(21.6 \%)$ worked in two or more of the units. Approximately one-half of the respondents $(n=38 ; 51.4 \%)$ had worked in geriatrics or geriatric psychiatry for more than 11 years. On average, in the previous three years, respondents participated in $1.5 \pm 1.16$ (range 0 to 5 ) pain-related continuing education initiatives (in-services, courses, workshops), committees or specialized projects. Listed activities were primarily formal pain and palliative care education, in-services on pain and depression, anxiety and somatization, and involvement on the GPP pain committee $(n=11)$.

\section{TABLE 1}

Results of survey questions related to pain assessment and management in the Geriatric Psychiatry Program, Regional Mental Health Care London, St Joseph's Health Care London, London, Ontario

\begin{tabular}{|c|c|c|c|c|c|}
\hline & $\begin{array}{c}\text { Strongly } \\
\text { disagree, } \\
\mathbf{n}(\%)\end{array}$ & $\begin{array}{c}\text { Disagree, } \\
\text { n (\%) }\end{array}$ & $\begin{array}{c}\text { Neutral, } \\
\text { n (\%) }\end{array}$ & $\begin{array}{c}\text { Agree, } \\
\text { n (\%) }\end{array}$ & $\begin{array}{c}\text { Strongly } \\
\text { agree, } \\
\text { n (\%) }\end{array}$ \\
\hline $\begin{array}{l}\text { Pain assessment is not } \\
\text { part of my role and } \\
\text { responsibilities }\end{array}$ & $\begin{array}{c}43 \\
(58.9)\end{array}$ & $\begin{array}{c}15 \\
(20.5)\end{array}$ & $\begin{array}{c}5 \\
(6.8)\end{array}$ & $\begin{array}{c}6 \\
(8.2)\end{array}$ & $\begin{array}{c}4 \\
(5.5)\end{array}$ \\
\hline $\begin{array}{l}\text { I find it difficult to assess } \\
\text { pain in the patients } \\
\text { in my program }\end{array}$ & $\begin{array}{c}9 \\
(12.2)\end{array}$ & $\begin{array}{c}30 \\
(40.5)\end{array}$ & $\begin{array}{c}12 \\
(16.2)\end{array}$ & $\begin{array}{c}19 \\
(25.7)\end{array}$ & $\begin{array}{c}3 \\
(4.1)\end{array}$ \\
\hline $\begin{array}{l}\text { I am confident in my ability } \\
\text { to assess pain in the } \\
\text { patients in my program }\end{array}$ & $\begin{array}{c}2 \\
(2.7)\end{array}$ & $\begin{array}{c}6 \\
(8.2)\end{array}$ & $\begin{array}{c}23 \\
(31.5)\end{array}$ & $\begin{array}{c}33 \\
(45.2)\end{array}$ & $\begin{array}{c}9 \\
(12.3)\end{array}$ \\
\hline $\begin{array}{l}\text { My unit has a standardized, } \\
\text { or consistent, approach } \\
\text { to assessing pain in patient }\end{array}$ & $\begin{array}{c}13 \\
(17.6) \\
\text { nts }\end{array}$ & $\begin{array}{c}35 \\
(47.3)\end{array}$ & $\begin{array}{c}13 \\
(17.6)\end{array}$ & $\begin{array}{c}9 \\
(12.2)\end{array}$ & $(2.7)$ \\
\hline $\begin{array}{l}\text { Pain is a problem for many } \\
\text { of the patients in my } \\
\text { program }\end{array}$ & 0 & 0 & $\begin{array}{c}9 \\
(12.2)\end{array}$ & $\begin{array}{c}42 \\
(56.8)\end{array}$ & $\begin{array}{c}22 \\
(29.7)\end{array}$ \\
\hline $\begin{array}{l}\text { Pain management could be } \\
\text { improved for patients } \\
\text { in my program }\end{array}$ & $\begin{array}{c}2 \\
(2.7)\end{array}$ & 0 & $\begin{array}{c}3 \\
(4.1)\end{array}$ & $\begin{array}{c}34 \\
(45.9)\end{array}$ & $\begin{array}{c}34 \\
(45.9)\end{array}$ \\
\hline $\begin{array}{l}\text { When pain is identified as a } \\
\text { problem, it is adequately } \\
\text { treated }\end{array}$ & $\begin{array}{c}3 \\
(4.1)\end{array}$ & $\begin{array}{c}24 \\
(32.4)\end{array}$ & $\begin{array}{c}19 \\
(25.7)\end{array}$ & $\begin{array}{c}21 \\
(28.4)\end{array}$ & $\begin{array}{c}6 \\
(8.1)\end{array}$ \\
\hline $\begin{array}{l}\text { My unit has a standardized, } \\
\text { or consistent, approach } \\
\text { to managing pain in patient }\end{array}$ & $\begin{array}{c}6 \\
(8.1) \\
\text { nts }\end{array}$ & $\begin{array}{c}36 \\
(48.6)\end{array}$ & $\begin{array}{c}15 \\
(20.3)\end{array}$ & $\begin{array}{c}12 \\
(16.2)\end{array}$ & $\begin{array}{c}2 \\
(2.7)\end{array}$ \\
\hline $\begin{array}{l}\text { In my program, all disciplines } \\
\text { are involved in pain } \\
\text { management }\end{array}$ & $\begin{array}{c}2 \\
(2.7)\end{array}$ & $\begin{array}{c}37 \\
(50.0)\end{array}$ & $\begin{array}{c}16 \\
(21.6)\end{array}$ & $\begin{array}{c}10 \\
(13.5)\end{array}$ & $\begin{array}{c}4 \\
(5.4)\end{array}$ \\
\hline $\begin{array}{l}\text { Pain assessment could be } \\
\text { improved for patients } \\
\text { in my program }\end{array}$ & 0 & $\begin{array}{c}1 \\
(1.4)\end{array}$ & $\begin{array}{c}4 \\
(5.4)\end{array}$ & $\begin{array}{c}37 \\
(50.0)\end{array}$ & $\begin{array}{c}28 \\
(37.8)\end{array}$ \\
\hline
\end{tabular}

Percentages do not sum to $100 \%$ due to missing values

\section{Pain assessment and management issues}

Table 1 presents results of selected survey questions related to perceptions of pain assessment and management in geriatric psychiatry. The majority of respondents (86.5\%) agreed ('agree' and 'strongly agree' ratings) that pain is a problem for many of their patients. Similarly, the majority agreed that pain assessment $(87.8 \%)$ and pain management $(91.8 \%)$ could be improved. Consistent with these findings, a small proportion of respondents agreed that their unit has a standardized or consistent approach to assessing (14.9\%) and managing (18.9\%) pain in patients in their program.

ANOVA revealed that compared with nursing, other disciplines had significantly higher mean $[ \pm \mathrm{SD}]$ scores related to perceptions that pain assessment is not part of their role and responsibilities, and that pain is difficult to assess in patients in their program (Table 2). Consistent with this, other disciplines had significantly lower mean scores than nursing related to their confidence in their ability to assess pain in their patients. RPNs had significantly higher mean scores than RNs related to their opinion that pain is adequately treated when identified. 
TABLE 2

Significant differences in perceptions of pain assessment and management by discipline

\begin{tabular}{|c|c|c|c|c|}
\hline & RNs & RPNs & Other & $\mathbf{F}$ \\
\hline \multicolumn{5}{|c|}{ Pain assessment is not part of my role and responsibilities } \\
\hline Mean \pm SD & $1.31 \pm 0.74$ & $1.76 \pm 1.13$ & $2.67 \pm 0.82$ & $9.49^{* * *}$ \\
\hline $\mathrm{n}$ & 26 & 29 & 15 & \\
\hline \multicolumn{5}{|c|}{ I find it difficult to assess pain in the patients in my program } \\
\hline Mean \pm SD & $2.36 \pm 0.94$ & $2.55 \pm 1.09$ & $3.44 \pm 1.21$ & $5.25^{\star *}$ \\
\hline $\mathrm{n}$ & 26 & 29 & 16 & \\
\hline \multicolumn{5}{|c|}{ I am confident in my ability to assess pain in the patients in my program } \\
\hline Mean \pm SD & $3.88 \pm 0.65$ & $3.72 \pm 0.75$ & $2.75 \pm 1.13$ & $10.49^{* \star *}$ \\
\hline $\mathrm{n}$ & 26 & 29 & 16 & \\
\hline \multicolumn{5}{|c|}{ When pain is identified as a problem, it is adequately treated } \\
\hline Mean \pm SD & $2.69 \pm 0.84$ & $3.45 \pm 1.12$ & $2.94 \pm 1.0$ & $4.08^{*}$ \\
\hline $\mathrm{n}$ & 26 & 29 & 16 & \\
\hline
\end{tabular}

${ }^{*} P<0.05,{ }^{* *} P<0.01,{ }^{* * *} P<0.001$. RNs Registered nurses, RPNs Registered practical nurses

There were several differences in perceptions based on years of experience in geriatrics. Those with less than one to five years of experience had significantly higher mean $[ \pm \mathrm{SD}]$ scores related to their belief that it was difficult to assess pain $(3.47 \pm 0.90)$, than those working in geriatrics for over 11 years $(2.30 \pm 1.1), F(2,67)=8.26, P<0.01$. Consistent with this, those with less than one to five years of experience had significantly lower mean ratings of confidence in their ability to assess pain in patients in their program $(3.05 \pm 0.85)$ than those working in geriatrics for six to 10 years $(3.64 \pm 1.0)$ and those working in geriatrics for over 11 years $(3.76 \pm 0.86), \mathrm{F}(2,67)=3.16, \mathrm{P}<0.05$. Those with less than one to five years of experience had significantly higher mean scores related to their belief that all disciplines are involved in pain management (3.11 1.2$)$ than those working in geriatrics for over 11 years $(2.51 \pm 0.89)$, $\mathrm{F}(2,67)=4.05, \mathrm{P}<0.05$.

\section{Barriers to pain management}

Overall, the majority of respondents agreed that most of the listed barriers exist in the GPP, with percentages of agreement ratings ranging from $(56.8 \%$ to $90.5 \%)$ (Table 3$)$. The exceptions were: 'low staff to patient ratios' and 'pain observations are not perceived as credible', for which $44.6 \%$ and $45.9 \%$ of respondents agreed, respectively.

There were no significant differences in ratings of agreement with the listed barriers to pain assessment and management by discipline or unit. Those staff members who had worked in geriatrics less than one to five years had higher mean scores of agreement related to lack of appropriate assessment tools $(4.17 \pm 0.71)$ than those with six to 10 years experience $(3.84 \pm 0.91), F(2,67)=4.22, P<0.05$.

\section{Pain indicators}

The majority of respondents (greater than 50\%) agreed that all of the symptoms/behaviours listed could be considered pain indicators with the exception that fewer respondents considered Cheyne-Stokes respirations $(37.8 \%)$, or being distracted or reassured by voice or touch $(43.8 \%)$, as pain related. The top ranking pain indicators were facial grimacing/wincing, verbal pain complaints, presence of a pain-related diagnosis, body positioning and groaning/moaning (Table 4).
TABLE 3

Number (percentage) of survey respondents that agreed and strongly agreed that listed barriers to pain assessment and management exist in their practice $(n=74)$

\begin{tabular}{lc}
\hline Common barriers to pain assessment and management & $\mathbf{n}(\%)$ \\
\hline Difficulty assessing pain in patients with communication & $67(90.5)$
\end{tabular}

impairments

Difficulty assessing pain in patients with cognitive impairments

Difficulty assessing pain in patients with delusional disorders

Difficulty assessing pain in patients with depression and other $61(82.5)$ affective disorders

Difficulty assessing pain in patients with psychosis

Difficulty assessing pain in patients with physical agitation/aggression

Misconceptions and attitudes about pain

$58(78.4)$

Lack of pain assessment tools that can be easily administered

Lack of documentation of pain symptoms/indicators

$55(74.3)$

$54(73.0)$

Lack of training related to pain assessment and management

Inconsistent monitoring of pain

$54(73.0)$

$53(71.6)$

Lack of appropriate assessment tools

$47(63.5)$

Lack of policies and standards related to pain assessment $45(60.8)$

and management

Reluctance to treat pain with nonpharmacological interventions

$43(58.1)$

Reluctance to treat pain with pharmacological interventions

$42(56.8)$

Pain observations are not perceived as credible

$34(45.9)$

Low staff to patient ratios

$33(44.6)$

Focus group interview

Interview participants attested that the results of the survey were consistent with their experiences and perceptions. There was general agreement that pain assessment within a geriatric psychiatry population is extremely difficult, as illustrated by the following comments:

"Sometimes we have patients that are really whiney all the time and they seem to be agitated. Is that a symptom of pain, or just their disease process and not necessarily pain? We don't seem to have any way to really determine whether it's pain or something else" (RPN).

"That's where we have a problem; we don't have a good tool. I mean, the charts are one thing because sometimes it gets mentioned, sometimes it's not. Looking at the symptoms, again that doesn't always indicate pain" (occupational therapist).

Change in normal behaviours and routines were thought to be an important indicator of pain; participants expressed an interest in an assessment measure that would assess the presence of pain indicators, but that would also identify changes from typical or usual behaviours, as illustrated in the following comment:

"So the checklist would have to indicate both, those [behaviours] present but also change, or there's got to be some way to capture that" (RN).

Failure to adequately assess and treat pain was attributed in part to the lack of a consistently used protocol or procedure. Allied health participants perceived themselves to lack training and experience to adequately identify pain in this population. Participants believed that in the absence of a protocol for assessment and management there was minimal accountability for pain. Although the potential presence of pain may be identified, they did not feel comfortable investigating this further. 
TABLE 4

Rank ordering* of pain indicators

\begin{tabular}{llccc}
\hline Ranking & Pain indicators & $\begin{array}{c}\text { Mean } \\
\text { (SD) }\end{array}$ & Range & $\begin{array}{c}\text { Agreement } \\
\mathbf{n}(\%)\end{array}$ \\
\hline 1 & Facial grimacing/wincing $(\mathrm{n}=74)$ & 4.51 & $3-5$ & $72(97.3)$ \\
& & $(0.56)$ & & \\
2 & Verbal pain complaints $(\mathrm{n}=74)$ & 4.41 & $2-5$ & $72(97.3)$ \\
& & $(0.59)$ & & \\
& & 4.41 & $3-5$ & $71(95.9)$ \\
& Presence of a pain related & $(0.55)$ & & \\
& diagnosis (arthritis, & & &
\end{tabular}

osteoporosis, hip fracture

cancer) ( $n=73$ )

Body positioning ('tense' or rigid posturing, avoiding certain positions, assuming protective posture) $(n=74)$ Groaning/moaning $(n=73)$

6 Wrinkling of the forehead in response to movement $(n=74)$

Protective behaviours (guarding or bracing of body parts $(n=74)$

Resistance to personal care that requires movement $(n=74)$

Reduced, or avoidance of movement or walking $(n=73)$

Changes in level of physical activity (pacing, wandering, fidgeting, inactivity) ( $n=74)$

Increased irritability ( $\mathrm{n}=74$ )

$\begin{array}{ccc}4.38 & 3-5 & 72(97.3) \\ (0.54) & & \end{array}$

$\begin{array}{ccc}4.37 & 2-5 & 70(94.6) \\ (0.57) & & \\ 4.36 & 2-5 & 72(97.3) \\ (0.59) & & \\ 4.36 & 3-5 & 70(94.6) \\ (0.59) & & \\ 4.28 & 3-5 & 71(95.9) \\ (0.54) & & \\ 4.26 & 3-5 & 70(94.6) \\ (0.53) & & \\ 4.19 & 2-5 & 66(89.2) \\ (0.66) & & \\ & & \end{array}$

$4.19 \quad 3-5 \quad 66(89.2)$

(0.61)

Increased restlessness $(n=74)$

Rubbing of body parts $(n=74)$

Crying ( $n=74)$

Changes in sleeping patterns (frequent waking, difficulty going to sleep, insomnia) $(n=74)$ Increased agitation $(n=74)$

Physiological changes to (temperature, blood pressure, flushing, pallor, diaphoresis) $(n=74)$

Changes in aggressive and resistive behaviours (presence of, increased, or reduced aggressive behaviours) $(n=73)$

Changes in eating habits (reduced eating, refusal to eat) $(n=74)$ Increased dependence on staff $(n=73)$

Distressed vocalizations (negative or disapproving quality) $(n=73)$

Changes in social activity (reduced social interactions, refuses social interaction) $(n=74)$
TABLE 4 - CONTINUED Rank ordering* of pain indicators

\begin{tabular}{|c|c|c|c|c|}
\hline Ranking & Pain indicators & $\begin{array}{l}\text { Mean } \\
\text { (SD) }\end{array}$ & Range & $\begin{array}{c}\text { Agreement }^{\dagger} \\
\text { n (\%) }\end{array}$ \\
\hline 23 & $\begin{array}{l}\text { Changes in level of cooperation } \\
\text { (uncooperative, indifference) }(n=74)\end{array}$ & $\begin{array}{c}4.01 \\
(0.67)\end{array}$ & $2-5$ & $62(83.8)$ \\
\hline 24 & $\begin{array}{l}\text { Changes in communication } \\
\text { (increased demands for } \\
\text { attention, reduced communication, } \\
\text { refusal to communicate) }(n=74)\end{array}$ & $\begin{array}{c}4.00 \\
(0.74)\end{array}$ & $2-5$ & $58(78.4)$ \\
\hline 25 & $\begin{array}{l}\text { Washing or dressing is laborious } \\
\text { and incomplete }(n=73)\end{array}$ & $\begin{array}{r}3.99 \\
(0.79)\end{array}$ & $2-5$ & $58(78.4)$ \\
\hline 26 & Rocking $(n=74)$ & $\begin{array}{c}3.92 \\
(0.87)\end{array}$ & $2-5$ & $53(71.6)$ \\
\hline 27 & Gasping sounds $(n=74)$ & $\begin{array}{c}3.89 \\
(0.73)\end{array}$ & $2-5$ & $56(75.7)$ \\
\hline 28 & $\begin{array}{l}\text { Inability to console, distract } \\
\text { or reassure }(n=74)\end{array}$ & $\begin{array}{r}3.89 \\
(0.74)\end{array}$ & $2-5$ & $53(71.6)$ \\
\hline 29 & Regressive behaviours $(n=74)$ & $\begin{array}{c}3.88 \\
(0.84)\end{array}$ & $2-5$ & $51(68.9)$ \\
\hline 30 & Increased confusion $(n=74)$ & $\begin{array}{c}3.86 \\
(0.83)\end{array}$ & $2-5$ & $51(68.9)$ \\
\hline 31 & $\begin{array}{l}\text { Asking for euthanasia; asking } \\
\text { to leave unit/hospital }(n=74)\end{array}$ & $\begin{array}{l}3.86 \\
(0.87)\end{array}$ & $2-5$ & $51(68.9)$ \\
\hline 32 & $\begin{array}{l}\text { Rapid breathing (or } \\
\text { hyperventilating) }(n=73)\end{array}$ & $\begin{array}{c}3.85 \\
(0.86)\end{array}$ & $2-5$ & $54(73.0)$ \\
\hline 33 & Noisy breathing sounds ( $n=73$ ) & $\begin{array}{l}3.75 \\
(0.80)\end{array}$ & $1-5$ & $50(67.6)$ \\
\hline 34 & $\begin{array}{l}\text { Changes in personal grooming } \\
\text { and appearance (dishevelled, } \\
\text { inappropriate clothes or grooming, } \\
\text { incomplete grooming) }(n=74)\end{array}$ & $\begin{array}{c}3.74 \\
(0.84)\end{array}$ & $2-5$ & $48(64.9)$ \\
\hline 35 & $\begin{array}{l}\text { Being distracted or reassured by } \\
\text { voice or touch }(n=73)\end{array}$ & $\begin{array}{l}3.39 \\
(0.89)\end{array}$ & $1-5$ & $32(43.8)$ \\
\hline 36 & Laboured breathing $(n=74)$ & $\begin{array}{c}3.22 \\
(0.72)\end{array}$ & $2-5$ & $52(70.3)$ \\
\hline 37 & $\begin{array}{l}\text { Cheyne-Stokes respirations } \\
\text { (characterized by rhythmic } \\
\text { waxing and waning of breathing } \\
\text { from very deep to shallow } \\
\text { respirations with periods } \\
\text { of apnea) }(n=74)\end{array}$ & $\begin{array}{c}3.22 \\
(1.10)\end{array}$ & $1-5$ & $28(37.8)$ \\
\hline
\end{tabular}

${ }^{*}$ As rated on a five-point rating scale $(1=$ strongly disagree, $5=$ strongly agree); higher means reflect higher agreement that the item is a pain indicator, 'AAgree' and 'Strongly Agree' ratings

Participants supported the development of a protocol or consistent approach for documenting concerns about potential pain, and for follow-up assessment and management to ensure that concerns or questions related to pain are addressed. Although it was suggested that a standard protocol could be implemented when screening proves positive for pain, participants also emphasized the need for regular pain assessments for all patients, even when pain has not been previously identified as a problem. Similarly, there was support for having pain incorporated into all treatment plans so that ongoing assessment becomes routine. Pain assessment as part of daily nursing routine was thought to provide a cue to look for it; pain assessment as part of documentation would ensure accountability. 
Desire for consistent pain monitoring and follow-up is evident in the following comments:

"(Regular assessment) every three months, or at the three month review, to have just the nurse think about. Although we haven't identified the pain problem up till now, maybe there's one that's developed in the last two weeks. So sort of forcing you to think about it" (RN).

"So, it goes through my mind every time we talk about that person, and 'what did we do and is it working?" (RN).

Participants were interested in developing a pain protocol or guideline, including a screening tool, to pilot test in the GPP. There was consensus that while self-report measures of pain could be appropriate for cognitively intact and communicative patients, behavioural measures should be used with patients who are cognitively impaired or noncommunicative, or when self-reports are not considered reliable.

\section{DISCUSSION}

Although there have been major advances in the past 30 years in the assessment and management of specific pain syndromes (eg, low back pain, cancer pain) and in specific populations (infants, children, adults), focus on pain issues in the elderly, in frail older persons and in older persons with cognitive impairment has only recently received attention. The findings from the present study suggest that pain in a geriatric psychiatry program is a problem for many patients, and that pain assessment and management could be improved. The study highlights the need for a standardized or consistent approach to assessing and managing pain in this clinical population. In the present study, barriers to pain assessment and management included difficulties associated with assessing pain in this clinical population, misconceptions and attitudes about pain, lack of appropriate and easily administered pain tools, and lack of consistent monitoring and documentation of pain. These issues and barriers are consistent with those identified in other clinical populations $(19,23)$. A study examining the perceptions of nursing staff on the status of pain assessment and management in their nursing home identified similar issues related to the lack of available pain assessment measures for seniors, and limited documentation of pain issues and management of pain (30). The findings from this study highlight the need for psychiatry programs to be cognizant of the need for better practices related to pain assessment and management for this population.

RNs in the present study were less challenged and more confident in their ability to assess pain than RPNs and allied health professionals, and those who had worked in geriatric psychiatry for many years were less challenged to assess and manage pain than those with less experience; however, challenges to pain assessment and management exist in the program regardless of discipline or experience. Continuing education focusing on learning strategies that promote knowledge transfer, such as peer mentoring, is one strategy for increasing the capacity of care providers to optimally assess and manage pain in this clinical population. However, in the absence of administrative policies, standardized protocols and documentation of pain, efforts to improve the quality of care will be minimal $(31,32)$.

Health care providers in the present study identified a number of behaviours that they perceived were indicative of pain in patients in the GPP. Many of these behaviours, such as facial expressions, verbalizations and body positioning are consistent with findings of other studies examining pain indicators in persons with cognitive impairment (15,33-35). A study examining behaviours indicative of pain in nursing home residents with dementia identified specific physical repetitive movements, vocal repetitions, physical signs of pain (discolouration, swelling, bleeding) and changes from normal behaviour as key pain indicators (35). However, these behaviours differ from the findings of other studies conducted with older persons with dementia. One study found that across all levels of dementia, pain was associated most often with anhedonia (absence of pleasure in activities that are normally enjoyable), depressed mood, withdrawal, low activities levels, low appetite and weight loss (36). While these conflicting results may highlight differences in pain perception dependent on the type of dementia (37), there may also be differences in the behavioural expression of pain between older persons with cognitive impairment and those with psychiatric illness, some of whom may be cognitively impaired. The fact that such a range of behaviours could be indicative of pain highlights the difficulties experienced by health care providers in interpreting behaviours as pain related.

What might be most relevant in the identification of pain indicators is not so much the specific behaviours themselves as changes in behaviour from the norm. In the present study, the majority of health care providers (more than $80 \%$ ) reported that changes in behaviour such as level of physical activity, sleeping patterns, aggressive and resistive behaviours, eating habits, social activity and level of cooperation were indicative of pain. The American Geriatrics Society panel on persistent pain in older persons also identified changes in interpersonal interactions and activity patterns as common pain behaviours in older persons with cognitive impairment (16). Behavioural measures that are sensitive to changes in mood and behaviour may accurately signal the development of a new or recurring pain problem that requires treatment.

A challenge associated with behavioural observation tools is the introduction of bias to the inference and interpretation of specific behaviours. Although the present study and others have identified a range of behaviours that can indicate pain, there is a need for clearly described pain behaviours so that health care providers can use uniform criteria to assess pain rather than simply their interpretations of behaviours. The Facial Action Coding Scheme describes in detail the facial expressions associated with pain in older persons to enable health care providers to objectively evaluate pain with minimal response bias (38), but an equivalent reliable and valid measure that operationally defines and describes a range of pain behaviours (other than facial expressions) does not yet exist. More research is needed to determine if this type of measure would be feasible or useful, or have greater clinical utility than a behavioural tool that simply lists potential pain behaviours leaving the definition of these behaviours open to interpretation.

There is much scientific evidence that pain perception is influenced by situational and psychological factors $(39,40)$. Behaviour may not be simply a passive reflection of pain intensity but may reflect other factors impacting on pain experience, such as distress, fear and anxiety. While the identification of relevant pain behaviours is essential when assessing pain in older adults who are unable to reliably report pain, it is also important to understand the context in which pain is occurring. Medical conditions, medications and other 
sources of distress in the environment may affect the validity of behavioural tools as meaningful measures of pain. Disentangling the sensory and affective components of pain can be challenging. Health care providers need to carefully consider the meaning of specific pain behaviours to ensure that they are relatively unaffected by the context and most reflective of changes in an individuals' pain experience. Observing and monitoring behaviour can provide a broad base of information about the factors that impact the pain experience and can better elucidate the nature of the pain problem. History taking that includes the identification of past and current conditions that may be painful, usual responses to pain, and effectiveness of drug and nondrug interventions used in the past can provide valuable information for understanding the meaning of pain behaviours (10).

The present study supports the need for a systematic, practical and consistent approach to pain assessment and management for older persons with cognitive impairment and psychiatric illness. The assessment of behavioural pain indicators are but one component of a comprehensive pain protocol for this population. Although both self-report and behavioural assessment tools may provide information about the presence of pain or even the effectiveness of treatment interventions, they provide no information about the nature of a person's pain (location, quality, duration, temporal variations, accompanying symptoms). In fact, there is evidence that health care providers can identify the presence of pain in older persons with cognitive impairment, but can not identify the strength or intensity of the pain (41). A more thorough approach to assessment is needed for this population that includes mechanisms for gathering more detailed and multidimensional information about pain experiences, such as structured interviews with family members (42). Moreover, there is a need to record and document pain behaviours, to document the outcome of drug and nondrug pain interventions, to re-evaluate pain and to revise the pain intervention plan accordingly. Although assessment methods may differ, the basic principles of pain management in adulthood are still relevant in older age.

One of the limitations of the present study is the overlap between cognitive impairment and psychiatric illness. Because many of the individuals in all of the units within the GPP experience some degree of cognitive impairment, it is not clear what distinct role, if any, psychiatric illness (eg, psychosis, schizophrenia, personality disorder) plays in the expression of pain. For example, there is evidence that persons with schizophrenia are insensitive to pain, but this is not well understood (43). Future research should attempt to differentiate psychiatric patients and patients with cognitive impairment to determine whether any difference in pain indicators exist, and to understand the factors (emotional, behavioural, environmental) that can impact or contribute to their pain experiences. Most importantly, there is a need to determine how this information can be used to establish reliable and valid methods of assessing pain and to develop effective interventions for reducing pain and improving quality of life. Another limitation to the present study is that although clinicians were asked to identify behaviours that indicate pain, their accuracy or confidence in using these indicators to identify pain in their patients was not assessed, but remains available for future study.

Highlighting the important role of research in supporting evidence-based practice and facilitating knowledge translation, the present study represents a positive step in translating research findings into viable clinical practices; the active engagement of clinicians in this process is reflective of our approach to supporting the use of knowledge in practice (44). Plans were put in place to entrust the development of a pain protocol for the GPP to a newly created interdisciplinary pain team within this program. Based on the premise that all staff should have the capacity to assess and manage pain, this pain team acts as a resource and support to staff efforts to assess and manage pain, rather than as a referral source for patients. The pain team is committed to using the results of the present study to develop a pain protocol/algorithm for regular and consistent screening and monitoring of pain from admission to discharge that incorporates the list of behaviours indicative of pain that were generated in the present and other studies. Further study of this newly created pain protocol/algorithm should examine concurrent and construct validity (comparing results with an accepted scale, and verifying that pain behaviours are reduced after analgesic administration, respectively). Pilot testing of this protocol will contribute to a greater understanding of the components of an effective, reliable and valid pain assessment and management strategy for this clinical population and will further inform development of the protocol.

ACKNOWLEDGEMENT: The authors are grateful for the participation in this study of staff members of the Geriatric Psychiatry Program (GPP) at Regional Mental Health Care London, St Joseph's Health Care London, London, Ontario.

FINANCIAL SUPPORT: This project was supported by a grant from the Department of Psychiatry, University of Western Ontario. This study originated in the Geriatric Psychiatry Program at Regional Mental Health Care London, St Joseph's Health Care London, London, Ontario

\section{REFERENCES}

1. Tsai PF, Chang JY. Assessment of pain in elders with dementia. Medsurg Nurs 2004;13:364-9.

2. Fox PL, Raina P, Jadad A. Prevalence and treatment of pain in older adults in nursing homes and other long-term care institutions: A systematic review. Can Med Assoc J 1999;160:329-33.

3. Feldt KS, Warne MA, Ryden MB. Examining pain in aggressive cognitively impaired older adults. J Gerontol Nurs 1998;24:14-22.

4. Horgas AL, Tsai PF. Analgesic drug prescription and use in cognitively impaired nursing home residents. Nurs Res 1998;47:235-42.

5. Scherder E, Oosterman J, Swaab D, et al. Recent developments in pain in dementia. BMJ 2005;330:461-4.

6. Cohen-Mansfied J, Lipson S. Pain in cognitively impaired nursing home residents: How well are physicians diagnosing it? J Am Geriatr Soc 2002;50:1039-44.

7. Stein WM, Ferrell BA. Pain in the nursing home. Clin Geriatr Med 1996;12:601-3.

8. Weiner D, Peterson B, Keefe F. Chronic pain-associated behaviors in the nursing home: Resident versus caregiver perceptions. Pain 1999;80:577-88.

9. Kovach CR, Weissman DE, Griffe J, Matson S, Muchka S. Assessment and treatment of discomfort for people with late-stage dementia. J Pain Symptom Manage 1999;18:412-9.

10. Hadjistavropoulos T, Herr K, Turk DC, et al. An interdisciplinary expert consensus statement on assessment of pain in older persons. Clin J Pain 2007;23:S1-43.

11. Pautex S, Michon A, Guedira M, et al. Pain in severe dementia: Self-assessment of observational scales? J Am Geriatr Soc 2006;54:1040-5.

12. Stolee P, Hillier LM, Esbaugh J, et al. Instruments for the assessment of pain in older persons with cognitive impairment. J Am Geriatr Soc 2005;53:319-26. 
13. Zwakhalen SM, Hamers JP, Abu-Saad HH, Berger MP. Pain in elderly people with severe dementia: A systematic review of behavioral pain assessment tools. BMC Geriatrics 2006;6:3.

14. Zwakhalen SM, Hamers JP, Berger MP. The psychometric quality and clinical usefulness of three pain assessment tools for elderly people with dementia. Pain 2006;126:210-20.

15. Fuchs-Lacelle S, Hadjistavropoulos T. Development and preliminary validation of the Pain Assessment Checklist for Seniors with Limited Ability to Communicate (PACSLAC). Pain Manag Nurs 2004;5:37-49.

16. American Geriatric Society Panel on Persistent Pain in Older Persons. The management of persistent pain in older persons. J Am Geriatr Soc 2002;50:S205-24.

17. Hadjistavropoulos T, LaChapelle DL, MacLeod F, Hale C, O'Rourke N, Craig KD. Cognitive functioning and pain reactions in hospitalized elders. Pain Res Manage 1998;3:145-51.

18. Hadjistavropoulos T, LaChapelle DL, MacLeod F, Snider B, Craig KD. Measuring movement-exacerbated pain in cognitively impaired frail elders. Clin J Pain 2000;16:54-63.

19. Clarke EB, French B, Bilodeau ML, Capasso VC, Edwards A, Empoliti J. Pain management knowledge, attitudes and clinical practice: The impact of nurses' characteristics and education. J Pain Symptom Manage 1996;11:18-31.

20. Cleeland CS, Cleeland LM, Dar R, Rinehardt LC. Factors influencing physician management of cancer pain. Cancer 1986;58:796-800.

21. Diekmann JM, Wassem RA. A survey of nursing students' knowledge of cancer pain control. Cancer Nurs 1991;14:314-20.

22. O'Brien S, Dalton JA, Knosler G, Carlson J. The knowledge and attitudes of experienced oncology nurses regarding the management of cancer-related pain. Oncol Nurs Forum 1996;23:515.

23. Vortherms R, Ryan P, Ward S. Knowledge of, attitudes towards and barrier to pharmacologic management of cancer pain in a statewide random sample of nurses. Res Nurs Health 1992;15:459-66.

24. Watt-Watson JH. Nurses' knowledge of pain issues: A survey. J Pain Symptom Manage 1987;2:207-11.

25. Mezinskis PM, Keller AW, Luggen A. Assessment of pain in the cognitively impaired older adult in long-term care. Geriatr Nurs 2004:25:107-12

26. Nunnally J. Psychometric Theory. New York, New York: McGraw Hill, 1978.

27. Kirk ARE. Experimental Design: Procedures for the Behavioral Sciences, 2nd edn. Belmont, California: Brooks/Cole, 1982.

28. Lincoln YS, Guba EG. Naturalistic Inquiry. Newbury Park, California: Sage Publications Inc, 1985.
29. Patton MQ. Qualitative Evaluation and Research Methods, 2nd edn. Newbury Park, California: Sage Publications Inc, 1990.

30. Martin R, Williams J, Hadjistavropoulos T, Hadjistavropoulos HD, MacLean M. A qualitative investigation of seniors' and caregivers' views on pain assessment and management. Clin J Nurs Res 2005;37:142-64

31. Herr K, Titler MG, Schilling ML, et al. Evidence-based assessment of acute pain in older adults. Clin J Pain 2004;20:331-40.

32. Registered Nursing Association of Ontario. Nursing Best Practice Guidelines. Assessing and Managing Pain. Toronto, 2002.

33. Mentes JC, Teer J, Cadogan MP. The pain experience of cognitively impaired nursing home residents: Perceptions of family members and certified nursing residents. Pain Manag Nurs 2004;5:118-25.

34. van Iersel T, Timmerman D, Mullie A. Introduction of a pain scale for palliative care patients with cognitive impairment. Int J Palliat Nurs 2006;12:54-9.

35. Cohen-Mansfield J, Creedon M. Nursing staff members' perceptions of pain indicators in persons with severe dementia. Clin J Pain 2002:18:64-73.

36. Ciper DJ, Clifford A, Roper KD. Behavioral manifestations of pain in the demented elderly. J Am Med Dir Assoc 2006;7:355-65.

37. Scherder EJA, Slaets J, Dijen JB, et al. Pain assessment in patients with possible vascular dementia. Psychiatry 2003;66:133-45

38. Hadjistavropoulos T, LaChapelle DL, Hadjistavropoulos HD, Green S, Asmundson GJ. Using facial expressions to assess musculoskeletal pain in older persons. Eur J Pain 2002;6:179-87.

39. Price DD. Psychological Mechanisms of Pain and Analgesia. Seattle: IASP Press, 1999.

40. Wall PD, Melzack R, eds. Textbook of Pain. London: ChurchillLivingstone, 1994.

41. Manfredi PL, Breuer B, Meier DE, Libow L. Pain assessment in elderly patients with severe dementia. J Pain Symptom Manage 2003;25:48-52.

42. Shega JW, Hougham GW, Stocking CB, Cox-Hayley D, Sachs GA. Pain in community-dwelling person with dementia: Frequency, intensity, and congruence between patient and caregiver report. J Pain Symptom Manage 2004:28:585-92.

43. Singh MK, Giles LL, Nasrallah HA. Pain insensitivity in schizophrenia: Trait or state marker? J Psychiatr Pract 2006;12:90-102.

44. Gauthier N, Ellis K, Bol N, Stolee P. Beyond knowledge transfer: A model of knowledge integration in a clinical setting. Healthc Manage Forum 2005;18:33-7. 


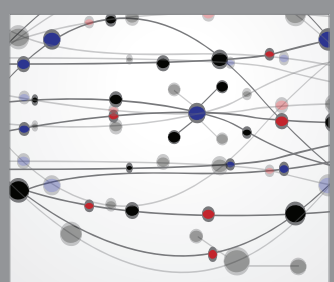

The Scientific World Journal
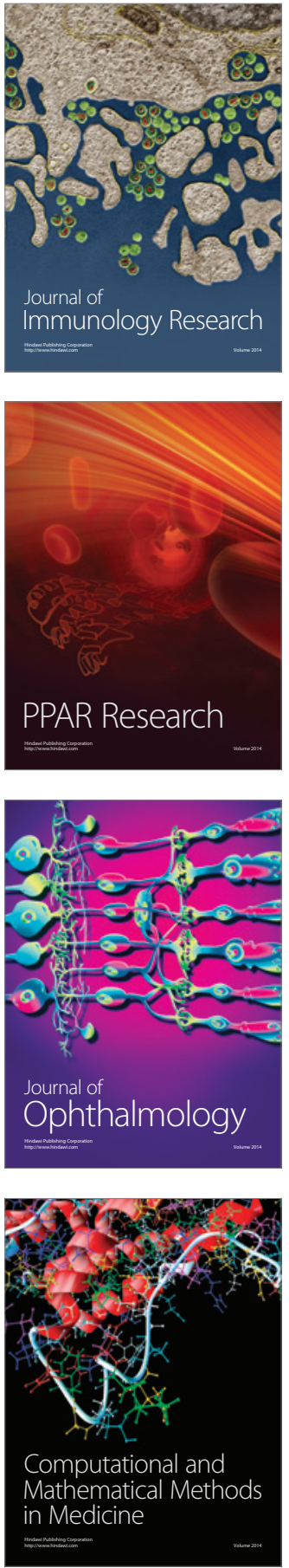

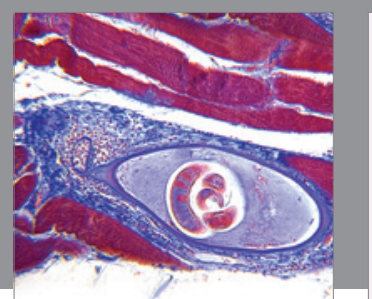

Gastroenterology Research and Practice

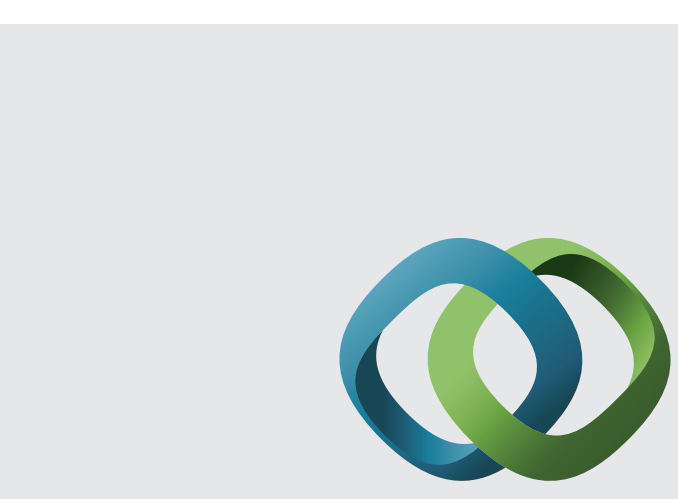

\section{Hindawi}

Submit your manuscripts at

http://www.hindawi.com
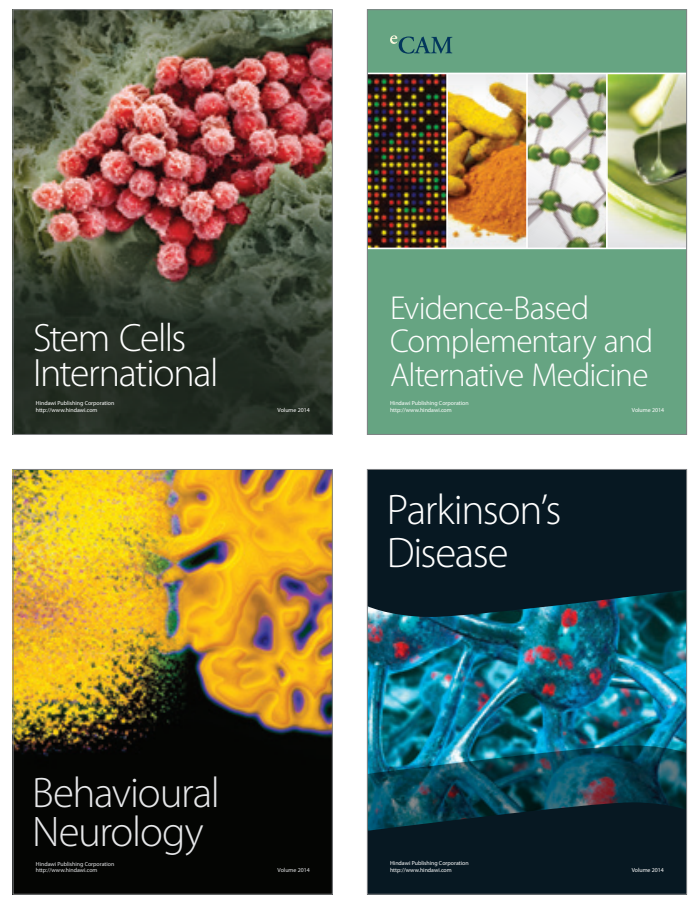
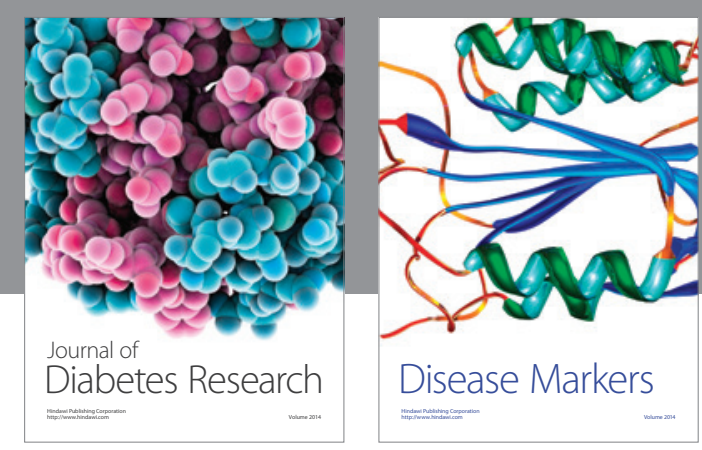

Disease Markers
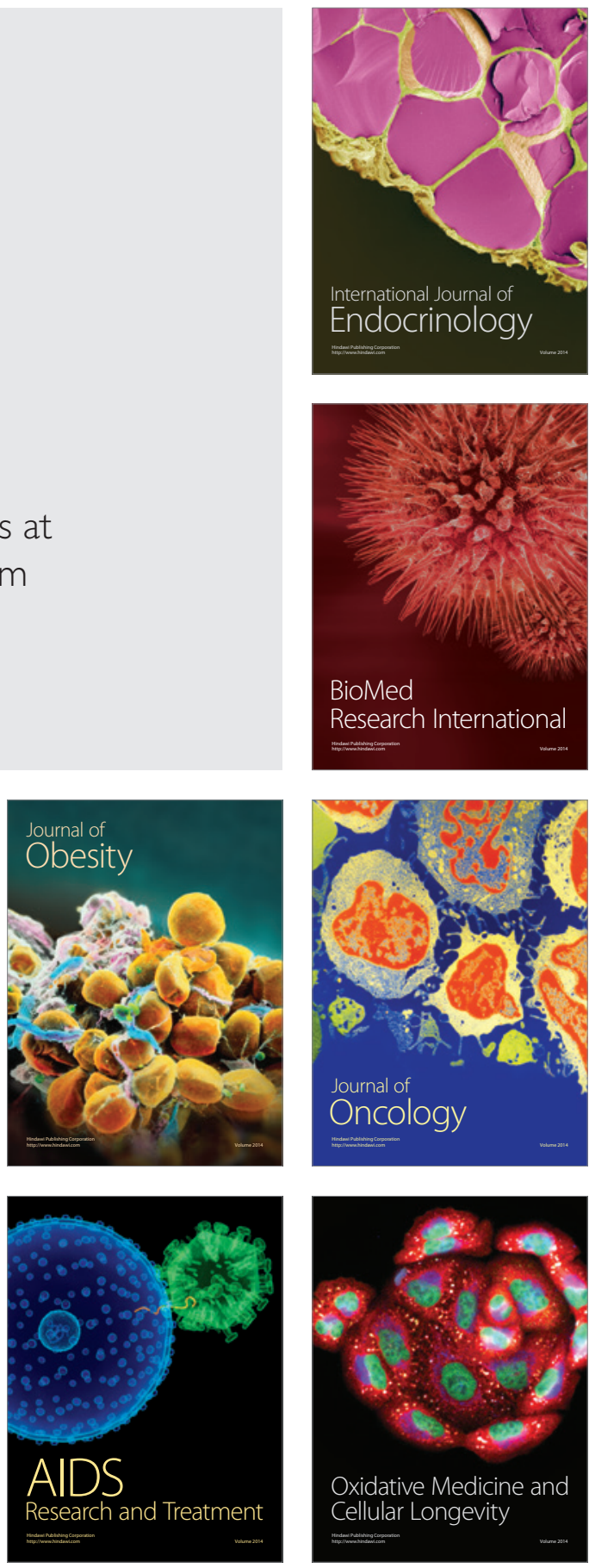